\section{Juvenile idiopathic arthritis and uveitis: the classification conundrum}

Although several isolated reports from the
fifteenth and sixteenth centuries identified arthritis in children, the first systematic description was by Georg Frederic Still in 1897 (reviewed by Southwood et al. ${ }^{1}$ ) whose name became eponymous for the disease. $\mathrm{He}$ presented a series of 22 cases of insidious-onset arthritis in children, which were associated with lymphadenopathy, fever, swinging pyrexia and splenomegaly. ${ }^{2}$ There was no description of associated eye disease. The association between intraocular inflammation and chronic arthritis in children was first documented by $\mathrm{Ohm}$ in $1910,{ }^{3}$ and confirmed by Friedlander. ${ }^{4}$ Since then it has become clear that there are several different forms of childhood arthritis, some of which are associated with either, or both, acute and chronic forms of anterior uveitis. The aims of this editorial are twofold: firstly to familiarise the ophthalmologist with the evolution of, and current proposals for, classification criteria for arthritis in children, and secondly to highlight the potential importance of these changes for the understanding of uveitis associated with childhood arthritis.

The first set of classification criteria for the diagnosis of 'Still's disease' was put forward by Ansell and Bywaters in $1959,{ }^{5}$ who felt that arthritis in children was the same as that seen in adults, contrary to Still's original opinion. They defined the arthritis as rheumatoid arthritis commencing before the age of 16 years, incorporating uveitis within their classification as a complication that was more damaging than that seen in adults. Throughout the next 30 years, the distinctions between adult and childhood arthritis became more defined, but European and North American classifications began to diverge.

In Europe, the Taplow criteria of 1968 recognised two subgroups of children with arthritis persisting for longer than 3 months: those with five or more (polyarticular), or four or fewer (pauciarticular) joints involved. ${ }^{6}$ The presence of uveitis was predominantly associated with the pauciarticular subgroup. In 1977, members of the European League Against Rheumatism (EULAR) introduced the term juvenile chronic arthritis (JCA), ${ }^{7}$ by which time,
SAAEHA RAUZ, PHILIP I. MURRAY, TAUNTON R. SOUTHWOOD in North America, the term juvenile rheumatoid arthritis (JRA) had been in use for almost 30 years. ${ }^{8}$ By 1977, the American College of Rheumatology (ACR) had approved, ${ }^{9}$ modified $^{10}$ and accepted proposals for the classification criteria of JRA.

Both JCA and JRA described a clinically heterogeneous group of idiopathic arthritides occurring in children under the age of 16 years, when all other causes, such as infection, autoimmune conditions, metabolic disorders (diabetes) or neoplasm had been excluded. Over the years, the terms JCA and JRA were used interchangeably, with the term 'Still's disease' occasionally being applied for the 'systemic' form of the disease. Yet the EULAR and ACR criteria did not describe identical disease spectra, and this led to confusion (Table 1). ${ }^{11}$ Although no correlation existed between activity of joint and eye inflammation, an association between the mode of onset of juvenile arthritis and subsequent risk of uveitis was recognised by both sets of criteria: systemic onset (with features such as quotidian (daily) fever, hepatosplenomegaly, lymphadenopathy or rash) carried the lowest risk, and the pauciarticular onset, the highest. ${ }^{12,13}$

There then followed extensive reviews in the literature from both sides of the Atlantic, examining the prevalence, disease course and prognostic indicators of uveitis associated with juvenile arthritis. The incidence had been reported as up to $21 \%{ }^{14-16}$ with $67-89 \%$ of these cases being bilateral. ${ }^{12,16,17}$ In the majority of the children, arthritis antedated the diagnosis of uveitis, which was usually asymptomatic and was frequently detected on routine slit-lamp examination. Visual loss had been reported in up to $66 \%$ of cases and ocular complications, such as band keratopathy, glaucoma, posterior synechiae, cataracts, maculopathy and phthisis bulbi in $75 \% .{ }^{19-23}$ There was increasing evidence that the prevalence and severity of uveitis associated with juvenile arthritis was decreasing, but there continued to be reports of poor vision at the time of first referral, with up to $26 \%$ of eyes having a visual acuity of $6 / 60$ or less. ${ }^{24,25}$ This finding endorsed the need for efficient screening programmes, with
S. Rauz

P.I. Murray

Academic Unit of Ophthalmology University of Birmingham Birmingham, UK

\section{T.R. Southwood} Chronic Arthritis and Rheumatic Diseases Unit University of Birmingham Birmingham, UK

Saaeha Rauz Academic Unit of Ophthalmology Birmingham and Midland Eye Centre City Hospital NHS Trust Dudley Road

Birmingham B18 7QU, UK Tel: +44 (0)121 5076851 Fax: + 44 (0)121 5076853 e-mail: S.Rauz@bham.ac.uk 
Table 1. A comparison of classification criteria for chronic arthritis in children

\begin{tabular}{lll}
\hline Characteristic & ACR & EULAR \\
\hline Age at onset & $<16$ years & $<16$ years \\
Minimal duration of arthritis & 6 weeks & 3 months \\
Subtypes & Pauciarticular & Pauciarticular \\
& Polyarticular & Polyarticular \\
& Systemic & Systemic \\
Rheumatoid factor & Does not alter classification & If present, called JRA not JCA \\
Spondyloarthropathies ${ }^{a}$ excluded & Yes & No \\
Other causes excluded & Yes & Yes \\
Name & JRA & JCA
\end{tabular}

ACR, American College of Rheumatology; EULAR, European League Against Rheumatism; JRA, juvenile rheumatoid arthritis; JCA, juvenile chronic arthritis.

${ }^{a}$ Spondyloarthropathies include juvenile ankylosing spondylitis, juvenile psoriatric arthritis, Reiter's syndrome and the arthropathies of inflammatory bowel disease.

examinations targeting high-risk populations, ${ }^{26}$ such as pauciarticular juvenile arthritis, young age of onset (less than 6 years), the presence of antinuclear antibody (ANA) and the female sex. ${ }^{27-29}$

Although these reports were invaluable in gaining an insight into the natural history of uveitis and the idiopathic arthritides of childhood, the lack of agreement in classification between Europe and North America had rendered the interpretation of clinical, epidemiological, serological and genetic data almost impossible. ${ }^{30}$ Three important limitations of the EULAR and ACR classifications were apparent: ${ }^{31}$ semantic (centring around the terms 'rheumatoid' and 'chronic' and the presence or absence of rheumatoid factor (RF))'; contextual (there was no clear definition or classification

Table 2. International League of Associations of Rheumatologists Classification

\begin{tabular}{llcc}
\hline Group & Disease & Uveitis & $\begin{array}{c}\text { ANA/ } \\
\text { HLA-B27 }\end{array}$ \\
\hline I & Systemic arthritis & No & No \\
II & $\begin{array}{l}\text { Oligoarthritis } \\
\text { Persistent }\end{array}$ & CAU & ANA \\
& Extended & & \\
III & Polyarthritis: RF negative & CAU & ANA \\
IV & Polyarthritis: RF positive & No & ANA \\
V & Enthesitis-related arthritis & AAU & HLA-B27 \\
VI & Psoriatric arthritis & CAU & ANA \\
& & (rarely AAU) & \\
VII & Other arthritis & No & No \\
\hline
\end{tabular}

AAU, Acute anterior uveitis; CAU, chronic anterior uveitis; ANA, antinuclear antibody; RF, rheumatoid factor.

Definitions

Arthritis: Swelling within a joint or limitation in range of joint movement with joint pain or tenderness, which is not due to primary mechanical disorders

Number of joints: Joints that are able to be individually evaluated clinically will be counted as separate joints

Oligoarthritis: Arthritis in one to four joints during the first 6 months

Polyarthritis: Arthritis in five or more joints during the first 6 months

Extended oligoarthritis: Arthritis in one to four joints during the first six months, and a cumulative total of five or more joints after the first 6 months of the disease

Enthesitis: Tenderness at the point of insertion of tendon, ligament, joint capsule or fascia into bone

ANA or RF positive: At least two positive results, 3 months apart, during the first 6 months of observation of disorders that were excluded, such as the spondyloarthropathies); and procedural (North American or European). The criteria had been developed and accepted regionally, rather than internationally, impeding their systematic evaluation, revision and validation, as well as making comparisons between therapeutic trials difficult; ${ }^{30}$ thus fuelling the classification conundrum.

Over the last 5 years a new classification has been proposed $^{32}$ and revised ${ }^{33}$ by an international taskforce convened by the World Health Organization and the International League of Associations of Rheumatologists (ILAR). The taskforce, consisting of rheumatologists and paediatricians, unified the language used to describe juvenile idiopathic arthritis (JIA), the term intended to replace both JCA and JRA. It defined clinically homogeneous subgroups of disease, in the hope that hitherto obscured underlying aetiological and pathogenetic factors would emerge to improve the understanding of the disease process. JIA, under the proposed ILAR classification, had several essential characteristics: arthritis beginning before 16 years of age, persisting for at least 6 weeks, in which no defined cause for the arthritis, such as sepsis or rheumatic fever, could be found. Seven potential subgroups could be identified on the basis of the disease pattern during the first 6 months after onset of the arthritis: systemic, oligoarthritis (four joints or fewer), polyarthritis (more than four joints) RF negative, polyarthritis RF positive, psoriatic arthritis, enthesitis-related arthritis, and other arthritides which fall outside, or fit more than one of, the six main categories. The oligoarthritis group was further subcategorised into persistent (affecting no more than four joints throughout the disease course) or extended (affecting a cumulative total of five joints or more after the first 6 months of disease). The option to gather further information was built into the classification through the use of 'descriptors', a defined further set of associated clinical and laboratory features which may help to revise the classification in the future.

The new classification poses an important challenge for ophthalmologists. Uveitis forms part of the definition, or one of the disease descriptors, for four of the seven ILAR categories: oligoarthritis, polyarthritis RF negative, psoriatic arthritis and enthesitis-related arthritis 
(Table 2). Although the uveitis associated with JIA is classically described as insidious, asymptomatic, chronic and non-granulomatous, the ILAR classification acknowledges symptomatic acute anterior uveitis as a distinct disease entity in the enthesitis-related arthritis group, and rarely in the psoriatic arthritis group. Detailed analyses of the natural history of the uveitis and incidence of ocular complications, or the general clinical features associated with uveitis within each of the ILAR categories, have not been undertaken. Whilst the majority of children with chronic anterior uveitis are found in the oligoarthritis group, how the two subcategories within this group, persistent and extended, differ from the ophthalmic point of view is at present unknown. Preliminary results from a United Kingdom cohort of 1025 children with JIA, revealed that 133 $(13.0 \%)$ had ocular involvement of which $70.7 \%$ had solely chronic anterior uveitis. Of these, $80.5 \%$ were found to be in the oligoarthritis group, with almost two-thirds of these in the persistent oligoarthritis subcategory (unpublished data).

It cannot be assumed that children with one particular clinical phenotype will necessarily have the same aetiological or pathogenetic mechanisms, and refinement of the classification criteria will be required. This should transpire when results of objective measures from laboratory variables (HLA and other genetic associations, infectious or serological abnormalities) become available from large clinical and laboratory databases of children with arthritis, such as that collected by the Twelfth International Histocompatibility Workshop. The ILAR taskforce aspires to develop unambiguous, clearly defined terminology, hoping to improve communication amongst all professionals involved in the management of JIA. The taskforce's ultimate aim is to develop criteria that would enable the identification of homogeneous groups of children with chronic arthritis, enhancing research in immunogenetics and other basic sciences, epidemiology, outcome studies, therapeutic trials and evidence-based medicine. Ophthalmologists could make their contribution to this international effort simply by prospectively and systematically evaluating children with uveitis and arthritis in accordance with the ILAR criteria $^{33}$ thereby facilitating the validation and acceptance process of the proposed classification.

\section{References}

1. Southwood TR, Woo P. Classification and nomenclature in juvenile arthritis. In: Silman and Symmons classification and assessment of rheumatic diseases. London: Baillière Tindall, 1995;9:331-5.

2. Still GF. On a form of chronic joint disease in children. Chirugial Transactions 1897;80:47. Reprinted: Am J Dis Child 1978;132:195-200.

3. Ohm J. Bandforminge Hornhauttrubung bei einem neunjahrigen Mädchem und ihre Behandlung mit subkonjunktivalen Jodkalinmeinspritzungen. Klin Monatsbl Augenheilkd 1910;48:243-6.

4. Friedlander A. Tilfaelde af kronisk septisk Polyartritis I Barnealderen med Ojenkomplikationer. 1933 Ugeskra Laeger 95:1190.
5. Ansell BM, Bywaters EGL. Prognosis in Still's disease. Bull Rheum Dis 1959;9:189-92.

6. Bywaters EGL. Diagnostic criteria for Still's disease (juvenile RA). In: Bennett PH, Wood PNH, editors. Population studies of the rheumatic diseases. Proceedings of the third international symposium. New York: Excerpta Medica Foundation, 1968:235-40.

7. EULAR Bull 4. Nomenclature and classification of arthritis in children. Basel: National Zeitung, 1977.

8. Coss JA, Boots RH. Juvenile rheumatoid arthritis: a study of forty-six cases with a note on skeletal change. J Pediatr 1946;19:143-56.

9. Brewer EJ, Bass JC, Cassidy JT, et al. Criteria for the classification of juvenile rheumatoid arthritis. Bull Rheum Dis 1972;23:712-9.

10. Brewer EJ, Bass JC, Baum J, et al. Current proposed revision of JRA criteria. Arthritis Rheum 1977;20:195-9.

11. Prieur AM, Petty RE. Definitions and classification of chronic arthritis in children. In: Southwood TR, Mallenson PN, editors. Arthritis in children and adolescents. London: Baillière Tindall, 1993:695-702.

12. Rosenberg AM, Oen KG. The relationship between ocular and articular disease activity in children with juvenile rheumatoid arthritis and associated uveitis. Arthritis Rheum 1986;29:797-800.

13. Kanski JJ. Juvenile arthritis and uveitis. Surv Ophthalmol 1990;34:253-67.

14. Goel KM, Shanks RQA. Follow-up study of 100 cases of juvenile rheumatoid arthritis. Ann Rheum Dis 1974;33:25-31.

15. Kanski JJ. Uveitis in juvenile chronic arthritis: incidence, clinical features and prognosis. Eye 1988;2:641-5.

16. Vesterdal E, Sury B. Iridocyclitis and band shaped corneal opacity in juvenile rheumatoid arthritis. Acta Ophthalmol 1950;28:321-7.

17. Smiley WK. The eye in juvenile rheumatoid arthritis. Trans Ophthalmol Soc UK 1974;94:817-29.

18. Stewart AJ, Hill BM. Ocular manifestations of juvenile rheumatoid arthritis. Can J Ophthalmol 1967;2:58-62.

19. Wolf MD, Lichter PR, Ragsdale CG. Prognostic factors in the uveitis of juvenile rheumoid arthritis. Ophthalmology 1987;94:1242-8.

20. Cassidy JT, Sullivan DB, Petty RE. Clinical patterns in chronic iridocyclitis in children with juvenile rheumatoid arthritis. Arthritis Rheum 1977;20:224-6.

21. Chylack LT, Bienfang DC, Bellows AR, et al. Ocular manifestations of juvenile rheumatoid arthritis. Am J Ophthalmol 1975;79:1026-33.

22. Key SN, Kymura SJ. Iridocyclitis associated with juvenile rheumatoid arthritis. Am J Ophthalmol 1975;80:425-9.

23. Cabral DA, Petty RE, Malleson PN. Visual prognosis in children with chronic anterior uveitis and arthritis. J Rheumatol 1994;21:2370-5.

24. Boone MI, Moore TL, Cruz OA. Screening for uveitis in juvenile rheumatoid arthritis. J Pediatr Ophthalmol Strabismus 1998;34:41-3.

25. Tugal-Tukan I, Havrlikova K, Power WI. Changing patterns in uveitis in childhood. Ophthalmology 1996;103:375-83.

26. Ophthalmic Services for Children. Report of a joint working party: the Royal College of Ophthalmologists and the British Paediatric Association, December 1994.

27. Reza Dana M, Merayo-Iloves J, Scaumberg DA. Visual outcomes prognosticators in juvenile rheumatoid arthritisassociated uveitis. Ophthalmology 1997;104:236-44.

28. Ohno S, Char DH, Kimura SJ, et al. HLA antigens and antinuclear antibody titres in juvenile chronic iridocyclitis. $\mathrm{Br}$ J Ophthalmol 1977;61:59-61.

29. Leak AM, Ansell BM, Burman SJ. Antinuclear antibody studies in juvenile chronic arthritis. Arch Dis Child 1986;61:168-72. 
30. Petty RE, Southwood TR. Classification of childhood arthritis: divide and conquer [editorial]. J Rheumatol 1998;25:1869-70.

31. Petty RE. Classification of childhood arthritis: a work in progress. Baillières Clin Rheumatol 1998;12:181-90.
32. Fink CW and the Taskforce for Classification Criteria. Proposal for the development of classificiation criteria for idiopathoic arthritides of childhoood. J Rheumatol 1995;22:1566-9.

33. Petty RE, Southwood TR, Baum J, et al. Revision of the proposed criteria for juvenile idiopathic arthritis: Durban 1997. J Rheumatol 1998;25:1991-4. 